\begin{tabular}{|c|c|}
\hline 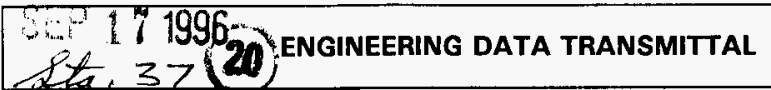 & 1. EDT 605674 \\
\hline
\end{tabular}

2. To: (Receiving Organization)

Distribution

5. Proj./Prog./Dept./Div.:

Waste Management
3. From: (originating organization) Retrieval Engineering 73530

6. Design Authority/ Design Agent/Cog. Engr : :

E. J. Bergl in
8. Originator Remarks:

This document is being processed for release.

11. Receiver Remarks: 11A. Design Baseline Document? [] Yes [X] No

4. Related EDT No.:

7. Purchase Order No.:

$N / A$

9. Equip./Component No.: N/A

10. System/Bldg./Facility: $N / A$

12. Major Assm. Dwg. No.: $N / A$

13. Permit/Permit Application No.: $N / A$

14. Required Response Date: $N / A$

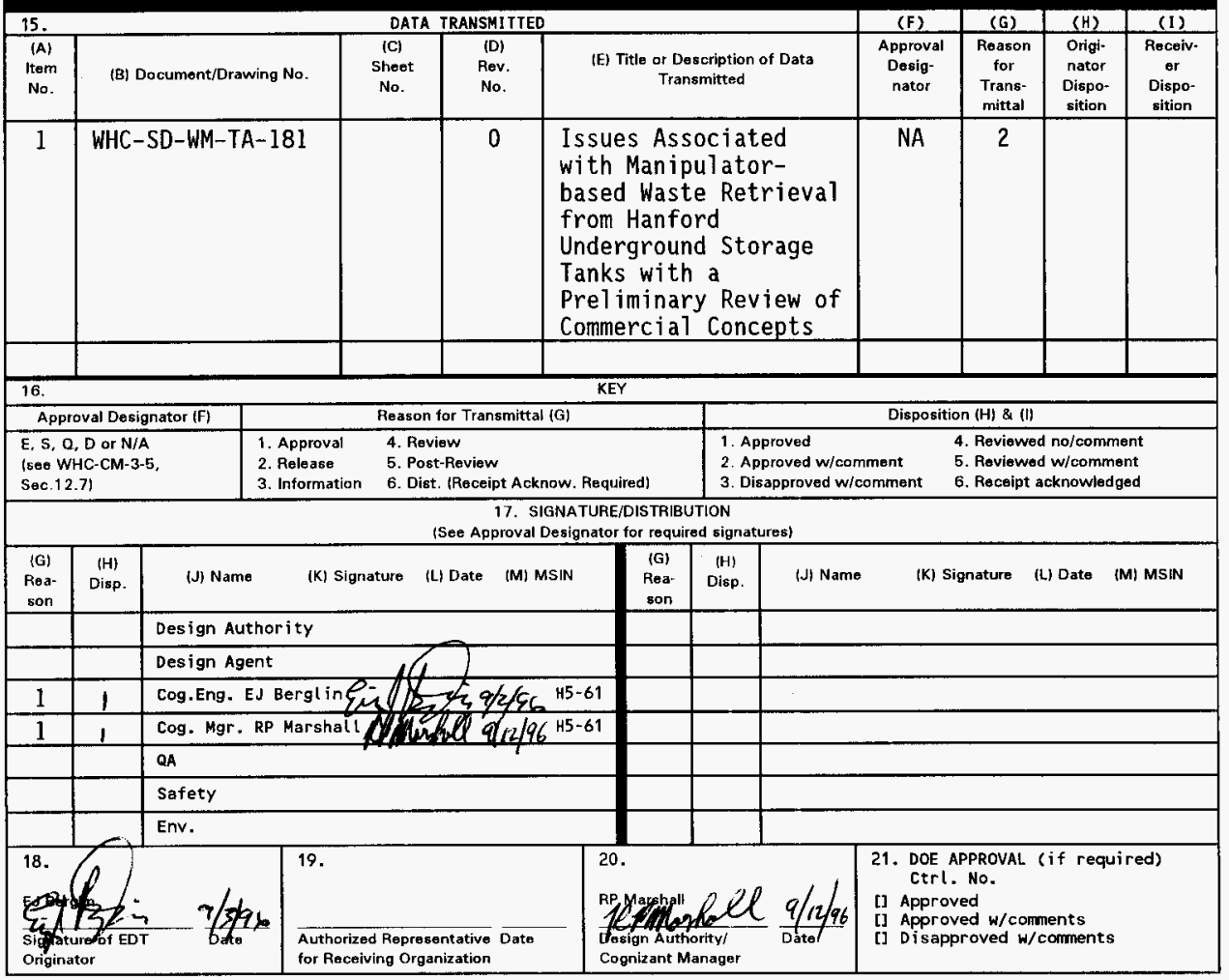




\title{
Issues Associated with Manipulator-Based Waste Retrieval from Hanford Underground Storage Tanks with a Preliminary Review of Commercial Concepts
}

\author{
Eric J. Berglin \\ Westinghouse Hanford Company, Richland, WA 99352 \\ U.S. Department of Energy Contract DE-AC06-87RL10930 \\ EDT/ECN: $605674 \quad$ UC: 2000 \\ Org Code: 73530 Charge Code: 02027 \\ B\&R Code: EW3130010 Total Pages: 29
}

Key Words: single-shell Tank, Waste Retrieval, SST, Acquire Commercial Iechnology for Retrieval, ACTR, Hanford Tank Initiative, HTI, Underground Radioactive Tank, Hanford, Manipulator, Deployment, Robotic Arm, Robot, Testbed Manipulator, GreyPilgrim, EMMA, Schilling, Magnox, EagleTech, Remote, Deploy, Access Tank

Abstract: The Acquire Commercial Technology for Retrieval program seeks commercial solutions to retrieve waste from large underground radioactive waste storage tanks using manipulator-based systems. This report provides a description of the need, requirements, and constraints for a manipulator-based retrieval system, evaluates manipulator based concepts and testing performed to date by a number of commercial organizations, and identifies issues to be resolved through testing and/or analysis for each concept. Five commercial companies manipulator concepts were reviewed based on existing technology and scaled up for use in tanks 75-ft in diameter by 54-ft high.

TRADEMARK DISCLAIMER. Reference herein to any specific comercial product, process, or service by trade name, trademark, manufacturer, or otherwise, does not necessarily constitute or imply its endorsement, recommendation, or favoring by the United States Government or any agency thereof or its contractors or subcontractors.

Printed in the United States of America. To obtain copies of this document, contact: WHC/BCS Document Control Services, P.0. Box 1970, Mailstop H6-08, Richland WA 99352, Phone (509) 372-2420; Fax (509) 376-4989.
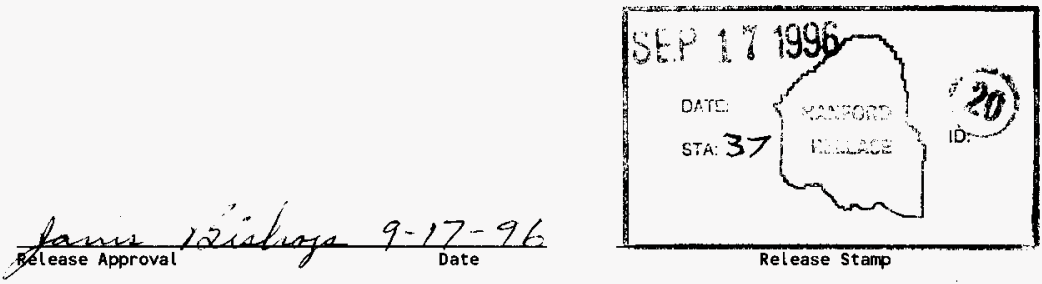

Approved for Public Release 
Issues Associated with Manipulator-Based Waste Retrieval from Hanford Underground Storage Tanks with a Prel iminary Review of Commercial Concepts

July 1996

E. J. Bergl in

prepared by

Dr. Mark S. Evans

Brigham Young University

Provo, Utah

\section{for}

Westinghouse Hanford Company

Richland, Washington 
WHC-SD-WM-TA-181 REV 0

CONTENTS

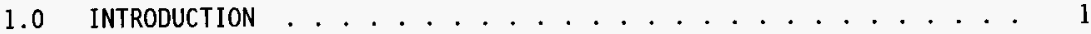

2.0 BACKGROUND AND PROBLEM DESCRIPTION . . . . . 1 2.1 HANFORD SINGLE-SHELL UNDERGROUND STORAGE TANKS . . . . . . I

3.0 SYSTEM REQUIREMENTS AND CONSTRAINTS . . . . . . . . . . 5

3.1 KINEMATICS ...................... . . . 5

3.2 ACCURACY/REPEATABILITY/DYNAMICS . . . . . . . . . 6

3.3 CONTROL ISSUES . . . . . . . . . . . . . . . 6

3.4 RADIATION ISSUES . . . . . . . . . . . . . . 7

3.5 RELIABILITY AND MAINTAINABILITY . . . . . . . . . . . 7

3.6 INTERFACES ..................... . . . 8

4.0 REVIEW OF COMMERCIAL CONCEPTS . . . . . . . . . . . . . 9

4.1 OVERVIEW . . . . . . . . . . . . . . . . . . 9

4.2 TESTBED MANIPULATOR . . . . . . . . . . . . . . . 9

4.3 GREYPILGRIM (EMMA) . . . . . . . . . . . . . 10

4.4 SCHILLING CONCEPT MANIPULATOR . . . . . ...... 11

4.5 MAGNOX CONCEPT MANIPULATOR . . . . . . . . . . . . . 12

4.6 EAGLETECH CONCEPT MANIPULATOR . ............ 13

5.0 CONCLUSIONS .................................. 14

6.0 REFERENCES ...................... 15 


\section{Abbreviations and Acronyms}

$\begin{array}{ll}\text { ACTR } & \text { Acquire Commercial Technology for Retrieval } \\ \text { ALC } & \text { airlift circulators } \\ \text { DOE } & \text { Department of Energy } \\ \text { DST } & \text { double-she1l tank } \\ \text { EMMA } & \text { name for GreyPilgrim manipulator } \\ \text { HTI } & \text { Hanford Tanks Initiative } \\ \text { ITH } & \text { in-tank hardware } \\ \text { PUREX } & \text { plutonium-uranium extraction } \\ \text { REDOX } & \text { reduction-oxidation } \\ \text { RTDP } & \text { Robotics Technology Development Program } \\ \text { SCARA } & \text { term for a specific robotic configuration } \\ \text { SST } & \text { single-shell tank } \\ \text { TFA } & \text { tanks focus area } \\ \text { TPA } & \text { Tri-party Agreement } \\ \text { WHC } & \text { Westinghouse Hanford Company }\end{array}$




\section{Issues Associated with Manipulator-Based Waste Retrieval from Hanford Underground Storage Tanks with a Prel iminary Review of Commercial Concepts}

\subsection{INTRODUCTION}

Westinghouse Hanford Company (WHC) is exploring commercial methods for retrieving waste from the underground storage tanks at the Hanford site in south central Washington state. WHC needs data on commercial retrieval systems equipment in order to make programmatic decisions for waste retrieval. Full system (i.e., integrated components) testing of retrieval processes is to be demonstrated in phases through September 1997 in support of two related programs: 1) Acquire Commercial Technology for Retrieval (ACTR) and 2) the Hanford Tanks Initiative (HTI).

One of the important parts of the integrated testing will be the deployment of retrieval tools using manipulator-based systems. WHC requires an assessment of a number of commercial deployment systems that have been identified by the ACTR program as good candidates to be included in an integrated testing effort. Included in this assessment should be an independent evaluation of manipulator tests performed to date, so that WHC can construct an integrated test based on these systems.

The objectives of this document are as follows: 1) to provide a description of the need, requirements, and constraints for a manipulator-based retrieval system; 2) to evaluate manipulator-based concepts and testing performed to date by a number of commercial organizations; and 3) to identify issues to be resolved through testing and/or analysis for each concept.

\subsection{BACKGROUND AND PROBLEM DESCRIPTION}

\subsection{HANFORD SINGLE-SHELL UNDERGROUND STORAGE TANKS}

Radioactive waste has been produced at the Hanford Site since 1944 as a by-product of processing spent nuclear fuel for the recovery of plutonium, uranium, and neptunium. The first waste storage single-shell tanks (SSTs) were completed and placed in operation in 1944. Between 1943 and 1964, 133 23-m (75-ft) diameter SSTs were built for the storage of radioactive wastes at the Hanford Site. These SSTs are located in 12 tank farms of 4 to 18 tanks each in the 200 West and 200 East Areas on the Hanford Site. No wastes have been added to the tanks since November 1980. However, water is added to tank 241-C-106 for evaporative cooling purposes. Pumpable interstitial 1iquid and supernatant wastes are being removed from SSTs and transferred to double-shell tanks (DSTs). 
At various times since 1944 , four major chemical processing operations have been conducted. Three of these processes, the bismuth phosphate, reduction-oxidation (REDOX), and plutonium-uranium extraction (PUREX) plant processes, were specifically designed for plutonium recovery. The more advanced REDOX and PUREX processes recovered the uranium as well as the plutonium. The fourth process, the tributyl phosphate process, was designed for the recovery of relatively large amounts of uranium that remained in the bismuth phosphate waste. These processing wastes, which contained most of the fission products and comparatively small quantities of uranium, plutonium, and other actinides, were originally stored as liquid wastes (with significant amounts of solids in the form of precipitated sludge) in the SSTs.

Liquid waste accumulation and storage in SSTs continued until 1980, when the DSTs were used exclusively for reçeiving new waste. The 133 SSTs presently contain more than $140,000 \mathrm{~m}^{3}$ (37 Mgal) of waste. In 1968, the interim stabilization program was started. This program removes the pumpable liquid from the SSTs, which results in a semi-dry sludge and saltcake-type residue. This program is primarily intended to reduce the leak potential of the SSTs.

Tank Configurations, Access: The Hanford Site has 133 SSTs that are $23 \mathrm{~m}(75 \mathrm{ft})$ in diameter. They range in height from 9 to $16 \mathrm{~m}$ (30 to $54 \mathrm{ft}$ ) (at their highest points) with nominal capacities of $1,900,2,850$, and $3,800 \mathrm{~m} 3(500,000,750,000$, and $1,000,000 \mathrm{gal})$. The maximum waste depths are 5,7 , and $9 \mathrm{~m}(17,24$, and $31 \mathrm{ft})$, respectively. A total of 2 to $2.4 \mathrm{~m}$ ( 6 to $8 \mathrm{ft}$ ) of earth cover each tank at the centerline of the dome. The minimum headspace (dome top to maximum liquid level) on the tanks is about $4 \mathrm{~m}$ (12 ft). The SST design has varied during a 30-yr construction schedule. The tanks are of reinforced concrete construction with 15-cm (6-in.) concrete floors, 33- to $60-\mathrm{cm}$ (13- to 24-in.) concrete walls, and 33- to $38-\mathrm{cm}$ (13- to 15-in.) concrete domes. The tank floor and walls are 1 ined with $6-$ to $10-\mathrm{mm}$ (1/4- to 3/8-in.) plate steel, while the concrete dome is unlined in most tanks. A small number of tanks have a steel dome liner.

Presently, access to the tanks is provided by risers penetrating the domes of the tanks and extending above grade. Although varying from tank to tank, the tanks were constructed with three general riser arrangements. Risers vary in size from 10 to $107 \mathrm{~cm}$ (4 to 42 in.) with 10 and $30 \mathrm{~cm}$ (4 and 12 in.) diameter being most common. All tanks have a center or near center riser of at least $30 \mathrm{~cm}$ (12 in.) in diameter. The number of currently available risers ranges from 0 to 11 , with the majority of tanks having 3 to 5 of the smaller sizes. Typically, tank domes contain a large number and variety of penetrations, not all of which extend up to the ground surface via risers. Additional or larger risers could be installed at or near the center of each tank or in a clear part of the dome with an obvious cost penalty. In addition, a cost penalty also exists for clearing existing obstructed risers and pits because many of the risers WHC may want to use contain saltwell screens, pumps, or other equipment. Internally, most of the tanks are relatively unobstructed, having only three to six in-tank structures, while two dozen or so are quite crowded. 
In-Tank Hardware (ITH): The retrieval system must either avoid, move, or work in the presence of ITH to retrieve the waste. The general categories of ITH are as follows:

- Fixed, built-in (permanently installed during tank construction)

- Fixed, riser installed (nominally removable, mounted through a riser)

- Loose items discarded in the tank (inaccessible for removal).

Twenty-one tanks have four built-in airlift circulators (ALC) each. The tanks have gas lines rising to the dome and guy wires angling off to the tank bottom as well as a half-dozen riser-mounted items. Four tanks are extremely congested with 22 riser-mounted ALCs plus a half-dozen additional items. Another dozen are moderately congested with 6 to 10 riser-mounted items. The remaining majority of tanks are relatively unobstructed with three to four peripherally mounted items and one or two center-mounted items. All tanks have loose material that has been discarded in the tanks. This material includes, but is not 1 imited to, pipe sections, fist-sized metal weights, 15-m (50-ft) stainless steel measuring tapes, and river rock.

In-tank equipment and discarded material need not be removed from the tank. There is a solid waste disposal cost penalty on removed equipment disposal.

Waste Types and Quantities: The majority of the wastes stored in SSTS was generated by chemical processing operations. Other wastes were sent to the SSTs in smaller volumes, and these include research and development program wastes, facility and equipment decontamination wastes, laboratory wastes, and Plutonium Finishing Plant wastes.

Subsequent waste management operations have created a complex intermingling of the tank wastes. Nonradioactive chemicals have been added to the tanks while varying amounts of waste and heat-producing radionuclides have been removed. In addition, natural processes have caused settling, stratification, and segregation of waste components. Waste was also cascaded (allowed to flow via gravity from one tank to another) through a series of tanks; cooling and precipitation of radionuclides and solids occurred in each tank of the cascade. As a result, it is very difficult, if not impossible, to precisely estimate the character of the wastes contained in the tanks from existing operational records.

The SSTs contain three general waste types; sludge, saltcake, and liquid. Sludge consists of the solids (hydrous metal oxides) precipitated from the neutralization of acid wastes before their transfer to the SSTs. Saltcake consists of the various salts formed after the evaporation of water from the neutralized alkaline waste. Liquids exist as supernatant and interstitial 1 iquid in the tanks. These waste types do not necessarily exist as discrete layers, but are intermingled to different degrees. Sludges and saltcake may contain interstitial liquids and be relatively soft. 0ther saltcakes and sludges may be drier and harder as a result of agglomeration or experimental addition of cement and various desiccants in an effort to prevent leakage. Sludge, saltcake, and liquid are thus used as general descriptions and classification of a waste as one waste form; however, this does not imply that the waste does not contain any of the other waste forms. 
The chemical constituents of the SST wastes consist primarily of sodium hydroxide; sodium salts of nitrate, nitrite, carbonate, aluminate, and phosphate; and hydrous oxides of iron and manganese. The radioactive components consist primarily of heat-producing fission product radionuclides such as $90 \mathrm{Sr}$ and $137 \mathrm{Cs}$, and actinide elements including uranium, plutonium, and americium and various relatively short-lived radioisotopes such as $106 \mathrm{Rh}$, $60 \mathrm{Co}$, and $125 \mathrm{Sb}$. These solid wastes (saltcake and sludge, with non-drainable interstitial liquid) vary considerably in physical consistency as well as in chemical and radionuclide content, not only from tank to tank, but within a tank as well.

The SSTs store a total of $140,000 \mathrm{~m} 3$ (37 Mgal) of waste. Of this waste, about 2,700 m3 (0.7 Mgal) are supernatant, 89,000 m3 (23.6 Mgal) are classified as saltcake, and $48,000 \mathrm{~m} 3(12.7 \mathrm{Mgal})$ are classified as sludge. The saltcake and sludge contain $34,000 \mathrm{~m} 3$ (8.9 Mgal) of drainable interstitial liquid. The bulk of the interstitial liquid, about 19,000 $\mathrm{m} 3$ (5 Mgal), is contained in saltcake and is being pumped to DSTs.

Waste Characteristics: Definitive physical parameters of the SST wastes are not presently available. A kaolin clay simulant and a potassium magnesium sulfate simulant have been developed as a limited representation of sludge and saltcake wastes. Photographs of the tank interiors show irregular surfaces for the wastes in some SSTS. Waste levels near the edges of tanks may be significantly higher than the center or where the removal of liquids has resulted in waste slumping.

Radioactive Source Terms: Dose rate estimates for the different tanks vary from 0.1 to $5 \mathrm{~Gy} / \mathrm{h}(10$ to $500 \mathrm{rad} / \mathrm{h})$ at the waste surface. Higher doses are expected below the waste surface. The dose at $>1 \mathrm{~m}(3 \mathrm{ft})$ from the surface is expected to be less than half of the surface reading. A dose level of several hundred $\mathrm{rad} / \mathrm{h}$ is a nominal expected range for most SSTs.

General Notes, Current Limitations, and Uncertainties: The retrieval of waste from the Hanford Site's SSTs is the subject of a Tri-Party Agreement with the Washington State Department of Ecology, the U.S. Department of Energy, and the U.S. Environmental Protection Agency. Currently, the Tri-Party Agreement has established a goal that at least $99 \%$ of the waste be removed; there are no requirements for the removal of ITH.

Direct, additional (total) loads on the SST domes exceeding approximately $445 \mathrm{kN}$ (50 tons) should not be imposed.

Direct, additional loads on the SST risers can generally not be tolerated by the weak riser to dome joint.

Requirements for additional risers and extensive site preparation should be minimized; however, the addition of access risers of various sizes is allowed, and may actually prove to be cost-effective in some system configurations.

The design of waste material-handling equipment can be based on the properties of two nonradioactive waste simulants, one sludge and one saltcake, conservatively derived from the opinions of operators during the 1960 s and 1970 s on the physical properties of the waste. These recipes are available upon request from WHC. 

hardened.

Equipment put into a tank does not necessarily have to be radiation

Undetermined downstream process requirements for initial pretreatment of waste before vitrification, and the following low- and high-level waste vitrification feed requirements, may impact the retrieved SST waste feed quantity and quality requirements.

Environmental, occupational radiological exposure, safety, and quality assurance considerations will be significant factors in the SST waste retrieval system design, development, and demonstration. Control of potential radioactive and hazardous emissions to the environment and personnel radiological exposure are of utmost importance.

\subsection{SYSTEM REQUIREMENTS AND CONSTRAINTS}

\section{1 KINEMATICS}

Deployment into Tanks: The kinematics of any manipulator used for retrieval of waste from underground storage tanks must allow for deployment of the manipulator into a full tank. It may be acceptable for a manipulator system to "mine" its way into a tank as part of this deployment process if it can be done in the presence of in-tank hardware (one of the tanks that is very nearly full is also one of the most congested in terms of fixed [immovable] in-tank hardware). A full tank will have at least $12 \mathrm{ft}$ of space between the top of the waste and the surface of the dome at the center of the tank. At the edge of a full tank (where the tank dome meets the tank wall) there is only about $2 \mathrm{ft}$ of head space, and at a $20-\mathrm{ft}$ radius from the center of the tank dome (a common location for access risers) there is about $10 \mathrm{ft}$ of head space.

Reach Requirements: The manipulator must be capable of positioning the waste dislodging and conveyance equipment to all locations throughout the tank that are necessary to retrieve all of the waste. For all of the manipulatorbased dislodging and conveyance concepts that have been developed thus far, this requirement translates into the ability to position the distal end of the manipulator to any point below the top of the tank liner with any orientation between horizontal (normal to the tank floor) and vertical (normal to the tank wa11). If other techniques are developed for the dislodging and conveyance of waste that result in other positioning and/or orientation requirements, then the manipulator must be capable of meeting these new requirements.

Dexterity/Mobility Requirements: The manipulator system should be capable of working in the presence of in-tank hardware. As mentioned above, some of the tanks are quite congested with vertical fixed in-tank hardware, much of which is connected to the floor of the tank. The manipulator must either be capable of working around such hardware, or removing it from its path. If the manipulator must remove the hardware from its path to gain access to all of the waste, this removal must be done in a timely manner (so as to not reduce the effectiveness of the waste retrieval process), and at the same time not put significant loading on the tank liner. 
Velocity Requirements: A manipulator must be capable of velocities that will sustain a retrieval rate of at least $30 \mathrm{gal} / \mathrm{min}$. This retrieval rate calculation is documented (Krieg et a1. 1990) and is based on the 6-mo time to actually retrieve the waste and a number of productivity engineering assumptions and judgments.

\subsection{ACCURACY/REPEATABILITY/DYNAMICS}

Accuracy/Repeatability: A manipulator system must have an accuracy and repeatability that will allow for the placement of the various end effectors in a manner that will sustain required retrieval rates and maintain the safety of the retrieval equipment and tank. The end effectors used and the accuracy and repeatability requirements for each will be dependent on the retrieval methods used. Significant work has been done in developing waste dislodging and conveyance technologies that may be suitable for deployment with manipulator systems (Rinker 1994).

Modal Separation: The natural frequencies for the modes of vibration for a manipulator system must be sufficiently separated from the frequencies produced by the waste dislodging and conveyance systems such that system productivity is maintained and system instability is avoided. The end effectors used and the amplitudes and frequencies of the forces/torques transferred to the manipulator system will be dependent on many factors including the retrieval methods used, the design of the end-effectors, the design of the manipulator system, and the design of the interface between the manipulator system and end-effectors. Some characterization of these forces/torques has been done for some waste dislodging and conveyance endeffectors (Rinker 1994). Significant work has also been done in the area of active oscillation damping in large manipulators as a supplement and/or alternative to modal separation (Hatchell and Mullen 1994, Lew 1994, 1996 and the Appendix).

Operating Bandwidth: The operating bandwidth of the manipulator system must be sufficient to support the retrieval operations, and to provide sufficient "feel of control" to the system operator. Large lags between the issue of operator commands and system response will greatly reduce the effectiveness of the retrieval operation. Both the bandwidths of the individual actuators (and hence their ability to respond to inputs from the control system) and the overall closed-loop bandwidth of the controlled system must be considered.

\subsection{CONTROL ISSUES}

Remote operation: Due to the extremely hazardous conditions that exist in the tanks, all of the retrieval operations performed inside of the tank must be done remotely. In addition, an operations performed outside of the tank that may pose a risk of contamination to either personnel or the environment will be performed remotely. The operator control station will need to be located a safe distance from the tank openings. 
World Model-Based Control/Man-Machine Interface: Visibility inside the tanks is poor due to the large volume resulting in large distances from reflecting surfaces. In addition, waste dislodging processes can result in airborne water and/or waste particles, and high radiation levels can cause poor performance of cameras and optics. It is therefore highiy recommended that the operator's view be supplemented with a computer graphics representation of the tank internals. Great care must be taken in data collection and model building in support of such a representation. This computer generated "world model" can also be used to provide computer oversight of the operator commands. Operator commands can be previewed for safety and performance issues, and the operator can be warned and/or restricted prior to performing operations that may be unsafe. A world mode1based control system also allows the operator more flexibility in selecting the viewing location and angle in order to "see" around or behind obstructions.

\subsection{RADIATION ISSUES}

Radiation Levels: All equipment to be used for retrieval of waste from the underground storage tanks be operated in the high radiation fields described in Section 2.1. The equipment should be capable of operating for sufficient time to complete the retrieval of waste from an entire tank without the need for part replacement due to failure caused by radiation exposure. This should be accomplished by a combination of minimizing the number of radiation sensitive components placed in the tank, shielding for radiation sensitive components that are placed in the tank, and modular replacement of radiation sensitive components between tanks.

Design for Decontamination: The manipulator system, end-effectors, and other equipment that will be placed in the tanks, should be designed for ease of decontamination. This can be accomplished by avoiding surfaces that are difficult to decontaminate, such as tight crevices or places where puddles form; minimizing the amount of equipment that actually comes in contact with the waste; and/or providing a disposable boot over equipment.

\subsection{RELIABILITY AND MAINTAINABILITY}

Reliability: The manipulator system must have a sufficient reliability to perform the tasks associated with retrieving all of the waste from a single tank without a system failure.

Maintenance: The manipulator system should be designed such that no scheduled maintenance is required during the retrieval of waste from a single tank. System components that are at a higher risk for failure should be designed for easy access and ease of remote maintenance. The manipulator should also be designed such that normal scheduled maintenance, to be performed between tank retrievals, can be performed as easily as possible while minimizing exposure to personnel.

Retrieval After Failure: It must be possible to retrieve the manipulator from the tank in the event that the system fails during operation. Manual intervention from the outside of the tank is permissible for this situation. 
Fail-safe: A manipulator system failure must not cause damage to the tank, create a safety risk to personnel, or allow a release of contamination to the environment.

\subsection{INTERFACES}

Accommodations for Dislodging and Conveyance Systems: The manipulator system must be designed to accommodate waste dislodging end-effectors and systems for conveying the waste to the height of the surface above the tank. These accommodations will include utility supply lines, waste conveyance lines, and attachments for supporting the weight and reaction forces of the end-effectors and conveyance lines. Careful consideration should be made with respect to the waste conveyance line in terms of access for maintenance and decontamination purposes.

Aboveground Structures: Aboveground support structures and equipment should not place more than the maximum allowable loads on the tops of the tanks. In addition, the structures should be capable of withstanding the high wind loads present on the Hanford site. Any aboveground structures, or equipment that is exposed to the inside of the tank or the waste, must include sufficient containment to protect workers and the environment from contamination.

Interface with the Tank: The manipulator system should access the tank through either an existing riser access port or through a new access port constructed specifically for the manipulator system. In either case, the interface between the inside of the tank and the outside of the tank (aboveground) must be properly designed to avoid the possibility of contamination to workers or the environment. This tank interface should include spray rings and/or other methods of decontaminating the exterior surfaces of the manipulator, waste dislodging end-effectors, and waste conveyance lines as they are retracted from the tank. The use of existing air filtration systems is acceptable if their capacity is not exceeded.

In-Tank Hardware (ITH): The Tri-Party Agreement (TPA) does not require the removal and/or disposal of ITH. The TPA considers the tank to be "clean" when no more than $360 \mathrm{cu} \mathrm{ft}$ of waste remains in the tank. Any waste entrained in the ITH following tank waste retrieval must be included as part of this residual waste. Therefore, it becomes important to remove as much waste from the surfaces of ITH as possible while not removing the ITH from the tank. The manipulator system must be capable of repositioning ITH within the tank if the ITH is cut as part of the retrieval process. 


\section{WHC-SD-WM-TA-181 REV 0}

\subsection{REVIEW OF COMMERCIAL CONCEPTS}

\subsection{OVERVIEH}

Concepts Reviewed: Five commercial concepts have been reviewed using some of the system requirements and constraints described above as evaluation criteria. This review has been conducted as part of the ACTR program. A general invitation was made to the commercial robotics community to provide concepts. Four of the five concepts reviewed were developed as a result of this invitation. One of the concepts was developed as part of the DOE Robotics Technology Development Program (RTDP) prior to implementation of the ACTR program, and was included in this review for completeness. It should be noted that the four concepts developed as part of the ACTR program were evaluated based on a "pre-conceptual" design using computer-graphics animations and the past experience of the commercial sources as inputs. The concept developed by the RTDP was developed through a detailed design phase and is therefore more mature in development than the others.

System Requirements and Constraints used as Evaluation Criteria: It was not possible to review the five concepts against all of the system requirements and constraints described in above sections, due to the preconceptual nature of the concepts. A common set of requirements and constraints was applied to each concept in order to be consistent in the evaluations. Each concept was evaluated for its ability to access the tank, its ability to be deployed in a full tank, its reach, dexterity, and aboveground support structure requirements.

\subsection{TESTBED MANIPULATOR}

The testbed manipulator was designed for the RTDP by Schiling Development Company (Hatchell and Mullen 1994). The system was designed to meet very specific performance criterion in order to meet all of the system requirements and constraints described in earlier sections of this report. The testbed manipulator was not designed to be used in a "hot" tank for actual waste retrieval, but was to be used in a full-scale tank mock-up as a research too1. Because of its research mission it was over-specified as far as its dynamic characteristics, control system, and data collection and analysis equipment.

The testbed manipulator was designed with a maximum diameter of 38 in. in order to fit through a 42-in. diameter, 15-ft long riser access port. The longest link of the testbed manipulator was to be 12 feet long, allowing it to be deployed in a full tank without the need of digging its way in, if inserted through a riser in the center of the tank. As only a small number of tanks have existing 42-in. diameter center access risers, the use of this manipulator would require the installation of a new riser for many of the tanks. If the testbed manipulator were to be placed in a side riser (on a 20-ft radius from the center of the tank for instance), its kinematics would allow it to dig its way in. 
The testbed manipulator was designed to be used as a gross positioning manipulator with a smaller, 6- to 9-ft reach manipulator, mounted on its distal end. The waste disiodging end-effector would be mounted to the distal end of the small manipulator and the waste conveyance line would be tethered along the length of the testbed manipulator and out the same access riser. The base of the testbed manipulator would be mounted on a mast providing it with vertical travel and rotation about the vertical axis of the mast.

The testbed manipulator consisted of three pitch joints, each of which pitched from about $-10 \mathrm{deg}$. to $90 \mathrm{deg}$. In addition, it had two roll joints, one between the base pitch joint and the second pitch joint, and the other near the end of the arm. Each roll joint could roll between $\pm 90 \mathrm{deg}$. The manipulator could be changed from an all elbows down configuration to either an all elbows right or all elbows left SCARA configuration by rotating these roll joints. The all elbows down configuration would be useful for digging into a full tank if needed, or for reaching the dome of the tank. The SCARA configurations provided dexterity for reaching around vertical ITH, with additional dexterity being provided by the smaller more dexterous manipulator. The dexterity of the large manipulator was limited, however, by the fact that it could only curl in one direction at a time, depending on the configuration of its roll joints.

The testbed manipulator had a total reach of $26 \mathrm{ft}, 8 \mathrm{in.}$, not including the vertical mast and the small dexterous manipulator. With a $9-\mathrm{ft}$ dexterous manipulator attached, the overall system could therefore reach $35 \mathrm{ft}, 8$ in. horizontally. With the addition of an end-effector this reach would be sufficient to clean the edge of the tank, if it was not required to reach around any ITH. Vertical ITH would, therefore, need to be cut and removed by the manipulator in order to completely clean many of the tanks.

Due to the need for a large vertical mast, the external support structure for the testbed manipulator would be quite large, extending $65 \mathrm{ft}$ or more above the supporting structure bridging the tank top.

\subsection{GREYPILGRIM (EMMA)}

GreyPilgrim, LLC, has developed a unique manipulator concept which may be applicable to tank waste retrieval if scaled-up from the current prototype. The current prototype has an overall reach of $8 \mathrm{ft}$, and would need to be scaled-up to at least $40 \mathrm{ft}$ to be effective (the scale-up length needs to be greater than $37.5 \mathrm{ft}$ due to the length of manipulator required for each bend). The manipulator is referred to as the EMMA manipulator and consists of three rigid sections connected by three flexible joints. Each joint is comprised of a flexible tube made of a urethane type material which is displaced by applying forces to a metal collar using six steel cables (Berglin 1996).

The EMMA manipulator technology is attractive for this application for several reasons including the following:

The manipulator is cable-driven, making it possible to remotely locate actuators. This may allow an EMMA manipulator to be deployed in a tank with the actuators located outside of the tank. This would be advantageous from a maintenance and decontamination view point. 
- The manipulator can be designed with a minimum of electronic components located in the tank.

- The manipulator could be easily booted to make decontamination as easy as possible.

- The center of the manipulator is an open channel which could be used to route either end-effector utility services, or waste conveyance 1 ines.

The diameter of a scaled-up EMMA manipulator has not been defined at this point, but an initial study has determined that a diameter of 1 foot may be possible for a 30-ft long manipulator. Obviously even if the diameter needs to be increased somewhat, this is very attractive for insertion into a tank through existing access risers.

While the longest single link of a 30-ft long EMMA manipulator would be $10 \mathrm{ft}$ long, it may still be difficult to deploy it into a full tank. This is due to the radius of curvature required to make a $90 \mathrm{deg}$ bend using a single joint. If the distal link is inserted and angled at $90 \mathrm{deg}$, it still maintains a vertical length due to this bend radius. The next link must be inserted into the tank before being bent, possibly causing the distal link to contact the waste before the second link can be bent. If the EMMA manipulator is outfitted with appropriate end-effectors it may be possible for it to mine its way into a full tank.

The EMMA manipulator would need to be mounted on some type of deployment mast just as the testbed manipulator. With a similar deployment mast, the EMMA manipulator could be designed to have the necessary reach. An important consideration in the design would be the length of manipulator required to make each bend due to the larger bend radius as compared to other manipulator designs. The effective length of the EMMA manipulator could possibly be increased by using a traditional pitch joint to connect it to its deployment mast. This would allow the manipulator to be placed in a horizontal plane without the bend radius problem.

Each joint of the EMMA manipulator is capable of bending in any plane (being able to essentially sweep-out a cone in space). This makes each joint of the EMMA manipulator very dexterous, with the overall dexterity of the manipulator limited by the number of joints. With only three joints, the overall dexterity of the manipulator may be less than the other two snake manipulators reviewed, each with more joints and shorter links (the Schilling concept and the Magnox manipulators). However, the dexterity of the EMMA manipulator may be sufficient for working around ITH.

The EMMA manipulator would require an aboveground support structure of roughly the same size as the testbed manipulator to house the manipulator and its vertical deployment mast.

\subsection{SCHILLING CONCEPT MANIPULATOR}

The Schilling concept manipulator consists of a vertical deployment mast providing both vertical and rotational motion, a base pitch joint, and six additional links connected with five sets of two axis gimbal joints. 
The Schilling manipulator has a maximum diameter of 36 in. and can, therefore, be inserted through a 42-in. diameter access riser. The longest link of the Schilling manipulator is 6-ft long, allowing it to be deployed in a full tank without the need of digging its way in, if inserted through a riser in the center of the tank or at a $20-\mathrm{ft}$ radius. As only a small number of tanks have existing 42-in. diameter access risers, the use of this manipulator would require the installation of a new riser for many of the tanks.

The Schilling manipulator is very dexterous due to the two axis gimbal joints that provide approximately \pm 45 degrees of pitch and yaw. There are five of these gimbal joints connecting six links. Each link is six feet long with an additional two pitch joints near at the distal end of the manipulator. This kinematic arrangement provides a high degree of dexterity for reaching through and behind vertical ITH. The drawback to this kinematic arrangement is the difficulty of controlling the manipulator using inverse kinematics. The only real practical method of controlling the manipulator will be to use a follow-the-leader approach. This would be practical and effective for teleoperation, but robotic operation would be very difficult without inverse kinematics.

The overall reach of the Schilling manipulator is $38 \mathrm{ft}-10$ in., without the vertical deployment mast. The manipulator would need a vertical deployment mast much the same as the testbed manipulator and the EMMA manipulator. With this arrangement the Schilling manipulator would be capable of reaching all areas of the tank from a central access riser while snaking around some ITH.

The aboveground support structure for the Schilling manipulator would need to be approximately twelve feet taller than that required for the testbed manipulator. This would extend 77 feet or more above the support structure.

\subsection{MAGNOX CONCEPT MANIPULATOR}

The Magnox manipulator is a concept developed by Magnox Electric, in Dartford, Kent, England. The manipulator consists of a 6 degree-of-freedom gross positioning manipulator, with a 9 degree-of-freedom dexterous manipulator mounted on its distal end. The gross positioning manipulator has an all pitch, elbows down configuration, and the dexterous manipulator has four links with four pitch joints, four roll joints, and one prismatic joint. The overall configuration provides for significant dexterity for reaching around and behind ITH in the dexterous manipulator, but limited dexterity in the gross positioning manipulator.

The vertical deployment mast is made from 6-ft long rigid links coupled together with rigid joints. This allows for compact aboveground storage by assembling/disassembling the rigid links as needed for vertical deployment. The entire aboveground structure can be placed on the back of a truck using a 27-ft tower.

The largest cross-section of the manipulator consists of a 12-in. by $18 \mathrm{in.}$ box section. This geometry allows for deployment in a 36-in. access riser with room for a waste conveyance system to pass through the same riser. 
The longest section of the Magnox manipulator is 6-ft long. This allows the system to be deployed into a full tank through either a center riser or risers on a $20-\mathrm{ft}$ radius. The deployment can be achieved without the need to dig its way in.

With the combination of the gross positioning and dexterous manipulators the overall reach of the system is sufficient to reach all locations within the tank.

\subsection{EAGLETECH CONCEPT MANIPULATOR}

The manipulator concept is proposed by EagleTech, Inc. The manipulator is comprised of a mobile bridge with a vertical boom assembly, knuckle assembly, jib boom assembly, and a dual-arm gripper. The vertical boom is affixed to the mobile bridge by a mobile undercarriage which has a three stage, 10-ft per stage, vertical movement to allow for opening/folding the manipulator above the tank and extending/retracting the manipulator into and out of the tank riser. The manipulator and its mobile undercarriage can traverse the full deck length of the movable bridge which can span a single tank.

The manipulator has a maximum diameter of $28 \mathrm{in}$. and would therefore be deployable through an access riser with a minimum diameter of 32 in. The longest link of the manipulator, when fully retracted, is the dual-arm gripper which is 11-ft long. The manipulator is capable of being inserted into a full tank without digging in if inserted through a center riser. The kinematics of the manipulator also make it possible to insert it through a side riser as it mines its way in.

The manipulator is not capable of "snaking" around vertical ITH. In a congested tank, such as $A X-104$, it would be necessary to cut vertical ITH out of the way in order to access all of the waste in the tank. The dual-arm gripper facilitates ITH cutting quite well, as one arm could hold and support the ITH while the other uses a waterjet or other type of cutter to cut.

The manipulator has an overall vertical reach of $51.5 \mathrm{ft}$ from the bottom of the bridge, and a horizontal reach of $39 \mathrm{ft}-11$ in. These overall reach capabilities and the kinematic arrangement of the manipulator make it capable of reaching all locations within the tank (provided that the ITH has been removed during the process).

The aboveground support structure would require a minimum overall height above the mobile bridge of $44 \mathrm{ft}$. 


\subsection{CONCLUSIONS}

Each of the manipulators reviewed have specific strengths and could be applied to the task of retrieving waste from the SSTs at Hanford. A summary and comparison of the manipulators is shown in Table 1. It should be noted that no weighting has been applied to the rankings that are shown in the table. As a result, the table should not be considered conclusive regarding which of the five designs are best, but rather to show that each has strengths and weaknesses when compared to each other.

Table 1 - Summary and Comparison of Manipulators Studied.

\begin{tabular}{||l|c|c|c|c|c||}
\hline \multirow{3}{*}{ Manipulator } & \multicolumn{5}{|c||}{ Rank (1 = highest, 5 = lowest) } \\
\cline { 2 - 6 } & Riser Access & $\begin{array}{c}\text { Full Tank } \\
\text { Deployment }\end{array}$ & Dexterity & Reach & $\begin{array}{c}\text { Aboveground } \\
\text { Structure }\end{array}$ \\
\hline Testbed & 5 & 4 & 5 & 5 & 3 \\
\hline EMMA & 1 & 5 & 3 & 4 & 4 \\
\hline Schilling & 4 & 1 & 1 & 2 & 5 \\
\hline Magnox & 2 & 1 & 2 & 1 & 1 \\
\hline EagleTech & 3 & 3 & 4 & 3 & 2 \\
\hline
\end{tabular}

The cost of the manipulator systems for retrieval from the SSTs ranges from $\$ 4 M$ to $\$ 6 M$. The EMMA manipulator likely costs less in terms of hardware, but significant development costs remain in order to reach the level of technical maturity of the other concepts.

The following are a list of general conclusions reached and insights gained as a result of this review.

- A tradeoff exists between the dexterity achieved as a result of a greater number of degrees of freedom (and/or the number of 1inks) and the controllability of the system. Manipulators with a greater number of shorter links are generally more adept at reaching around and behind vertical ITH. In contrast, manipulators with fewer joints are easier to control.

- It appears that it is possible to develop manipulator systems that are capable of accessing many of the tanks through existing risers.

- It appears that it is possible to develop manipulator systems that are capable of being deployed into full tanks. 


\section{WHC-SD-WM-TA-181 REV 0}

- An arm must be somewhat longer than $37.5 \mathrm{ft}$ (if deployed from the center of the tank) to reach the edge of the tank if it must snake around ITH. The extra length required will be dependent upon the type of joints, the number of curves required, and which joints are used to make the curves.

- It should be noted that while some of the issues raised are important for some tanks, they may not be important for others. One example is the ability to deploy in a full tank. Most of the tanks are not full, but a few are.

One final and very important note that should be made is that this review is based on very prefiminary, pre-conceptual design information. It is hoped that the findings of this review provide a basis for further development and study if manipulator-based retrieval of waste from SSTs at Hanford is determined to be a method of choice.

\subsection{REFERENCES}

Berglin, E. J., 1996, Test Results for Robotic Manipulator EMMA, WHC-SD-WM-TD012 , Dr. Ronald E. Graham, GreyPilgrim, LLC, for Westinghouse Hanford Company, Richland, Washington.

Hatche11, B. K. and 0. D. Mullen, 1994, Robotics Technology Development Program Technical Summary, D0E/EM-0127P, U.S. Department of Energy, Washington D.C.

Krieg, S. A., W. W. Jenkins, K. J. Leist, K. G. Squires, and J. F. Thompson, 1990, Single-shell Tank Waste Retreieval Study, WHC-EP-0352, UC-721, Westinghouse Hanford Company, Richland, Washington.

Lew, Dr. Jae Y., 1994, The Effect of Passive Damping on Feedback Control Performance in Flexible Manipulators, PNL-SA-23330, Pacific Northwest National Laboratory, Richland, Washington.

Lew, Dr. Jae Y., 1996, Experimenta7 Study on Micro/Macro Manipulator Vibration Contro7, PNNL-SA-27368, Pacific Northwest National Laboratory, Richland, Washington.

Rinker, M. W., 1994, Waste Dislodging and Conveyance Testing Summary and Conclusions To Date, PNL-10095, Pacific Northwest National Laboratory, Richland, Washington.

\section{CONTACTS}

Lew, Dr. Jae Y., Senior Research Scientist, Robotics and Mechanical Systems, Pacific Northwest National Laboratory, P.0. Box 999, Richland, WA 99352 , (509) 375-4489.

Rinker, M. W., Technica1 Lead, Waste Dislodging and Conveyance, Pacific Northwest National Laboratory, P.0. Box 999, Richland, WA 99352, (509) 375-6623. 
APPENDIX: DAMPING CONTROL OF A LARGE FLEXIBLE MANIPULATOR THROUGH INERTIAL FORCES OF A SMALL MANIPULATOR

PNL-SA-22041

\author{
D. J. Trudnowski \\ C. P. Baker \\ M. S. Baker \\ Pacific Northwest Laboratory \\ Richland, Washington
}




\title{
Damping Control of a Large Flexible Manipulator Through Inertial Forces of a Small Manipulator
}

\author{
D.J. Trudnowski, C.P. Baker, M.S. Evans. \\ Pacific Northwest Laboratory" \\ PO Box 999 \\ Richland, Washingron 99352
}

\begin{abstract}
Damping control is applied to a detailed computer model of a long reach flexible manipulator test-bed. The test bed consists of a long slender link with a dextrous manipulator mounted at its tip. The movement of the dextrous manipulator is controlled to create inertial damping forces on the long link. Parameter jdentification and sequential loop-closure are used to design a controller that feeds back relative tip position and velocity of the long link to control the azimuth angle of the dextrous manipulator. The controller is designed to be robust to varying manipulator loading conditions and reliable under sensor failures.
\end{abstract}

\subsection{INTRODUCTION}

The remediation of hazardous waste sites at US Department of Energy facilities will require the use of remote equipment. Due to conditions at some of these waste sites, remotely operated manipulators with reach capabilities greater than thirty feet will be needed. Access restrictions for these manipulators, particularly in large underground storage tanks, will result in manipulators with relatively flexible links and low natural frequencies of oscillation. In order to effectively use such manipulator systems, damping control techniques are need to subside significant system oscillations. A long reach flexible manipulator test-bed, and associated facilities at Pacific Northwest Laboratory (PNL), are making possible the development and testing of active damping control systems for long reach manipulators. This paper presents a short description of the test bed, and simulation results of a damping control system for the test bed.

One class of long reach manipulators being considered for waste remediation is configured as a coarse positioning long reach manipu- lator (LRM) with a more dexterous, lighter duty short reach manipulator (SRM) mounted on its tip. A laboratory test-bed for this configuration is shown in Figure 1.

The control system presented here controls the motion of the SRM to generate inertial forces designed to annihilate the oscillations sensed in the flexible LRM tip. The LRM's fist three modes of oscillation are damped by feeding back the tip's relative position and velocity to control the azimuth angle of the SRM. The controller is designed using parameter identification and sequential loop-closure. The control system is required to be robust in that it must provide damping over a wide range of loading conditions. It is also required to be reliable in that it must still perfom well in the presence of sensor or loop failures.

Very little research has been conducted on using SRM movements to dampen oscillations in the LRM, although it has been proposed by Book [1]. Considerable work has been performed on controlling other configurations, especially damping oscillations through modulation of a long-reach manipulator's hub motor (for a sample see [2] and [3]).

Classical frequency response and rootlocus methods are used to choose the parameters of the individual loop controllers applied in this paper. These methods are used as system robustness and reliability can more easily be incorporated into the design.

Other methods that have been proposed for damping oscillations in mechanical systems include state-space (e.g., LQG and pole placement) and adaptive methods. Some researchers have noted that state-space controllers perform very poorly as the operation of the system devi-

- Operated for the U.S. Department of Energy by Battelle Memorial Insitute under Contract DE-AC06-76RLO 1830. Work supported by the U.S. Department of Energy's Office of Technology Development. 


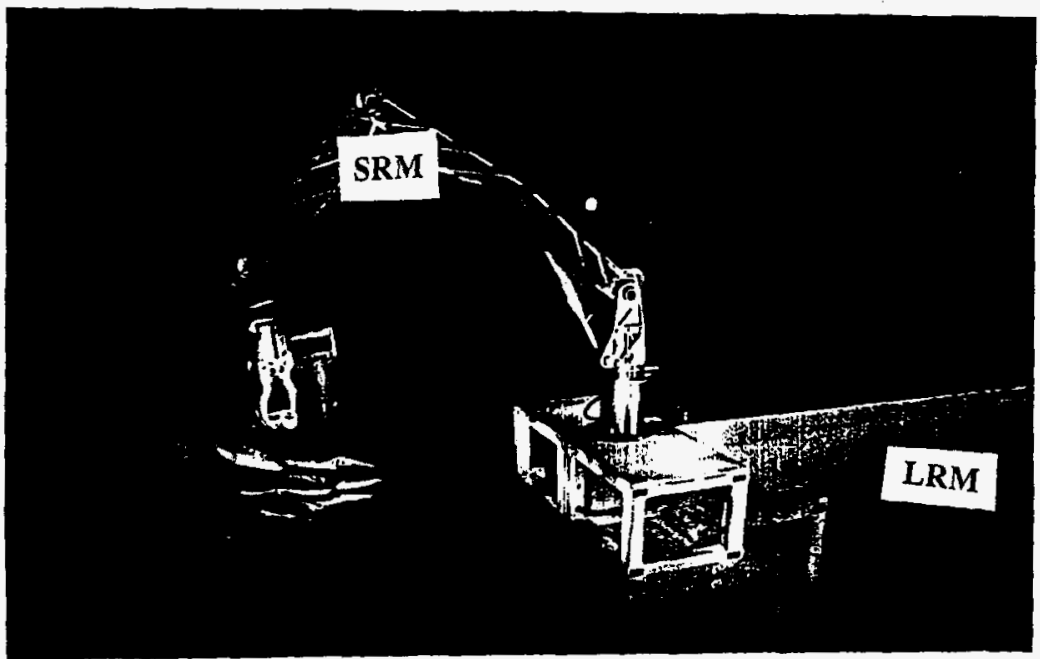

FIGURE 1. Flexible Manipulator Test-bed

ates from the design condition [4]. While some favorable results are presented in [2] for adaptive control, an observed disadvantage is that initial oscillations often occur before the gains of the controller converge to their proper values [5]. For these reasons, a more classical approach is proposed here.

The remainder of this paper is organized as follows. The test-bed is briefly described in Section 2.0. Control system design issues are outlined in Section 3.0. Section 4.0 addresses system modeling, and the controller design methodology is discussed in Section 5.0. Finally, simulation results are presented in Section 6.0, and conclusions made in Section 7.0.

\subsection{TEST BED}

One type of robotic system being considered for waste remediation is configured as a coarse-positioning long-reach manipulator (LRM) with a more dexterous, lighter duty shortreach manipulator (SRM) mounted on its tip. Each link of the LRM would be from eight to ifteen feet long. The long reach flexible manipula- tor test-bed shown in Figure 1 simulates the last link on such an LRM with the SRM mounted on its end. Figure 1 shows the SRM and the end portion of the LRM. The test-bed consists of a steel beam representing the $L R M$ which is 15 feet long by 1 foot high by 0.75 inches thick, fixed at one end and free to move in a horizontal plane at the other. The free end is supported off the floor by an air bearing which provides a low friction interface with the floor while restricting any torsion about the longitudinal axis of the beam. Limiting the torsion in the beam in this manner is necessary to avoid buckling. A six-degree-offreedom hydraulic manipulator (Schilling Titan $7 F$ ) is mounted on the bean at the free floating end to represent the SRM. A more detailed description of the test-bed is contained in [6].

To develop and test control algorithms prior to implementation on the test-bed, a dynamic model of the cest-bed has been developed using DADS (a dynamic modeling and sinulation software package developed by CADSI, Inc.). Control algorithms can be tested and evaluated via computer simulation prior to implemen- 
tation on the test-bed hardware. The DADS model of the test-bed uses results from the ANSYS finite-element code to model the fiexible body dynamics of the system. The flexible body results are incorporated into the DADS model, which also incorporates the mass and inertia properties of the SRM, air bearings, and other hardware. The system flexibility and nanural frequencies predicted by DADS are comparabie with those observed in the lab.

\subsection{CONTROL DESIGN ISSUES}

The damping control system presented here controls the motion of the SRM to generate inerial forces on the tip of the LRM. This problem is challenging as many considerations must be addressed; some of the more critical issues include:

1. Flexible mechanical structures can oscillate at an infinite number of modes. With the PNL test-bed, the first few modes dominate; therefore, a controller must damp these modes while having very little or no detrimental effect on other modes.

2. The dynamic and kinematic interactions between the LRM and the SRM are nonlinear and complex. Therefore, it can be extremely difficult to accurately model.

3. System oscillations can be initiated by a variety of excitations including exogenous disturbances and operator-controlled movements. While operator-controlled movements can be tempered and smoothed, unknown disturbances such as impact with unseen objects are impossible to predict,

4. Loading conditions and system configurations may vary during manipulator operation. With each new load and configuration, the dynamic response the system changes. Therefore, a control system must provide damping under a wide variety of operating conditions (i.e., the controller must be robust to varying system conditions).

5. Because measurement and operating systems are prone to partial failures (e.g., sensor failure), the control system must satisfactorily operate under various mea- surement errors and system failures (i.e., the controller must be reliable).

Figure 1 shows the structure of the damping control system. The relative tip position and velocity of the LRM are measured and then passed through controllers $H_{p}$ and $H_{v}$, respectively. The outputs of the controllers are subtracted from the desired steady-state azimuth angle $\left(\theta_{d}\right)$, and then passed to the SRM as the desired azimuth angle. The objective is to design $H_{p}$ and $H_{z}$ to satisfactorily address the five issues listed in the previous section. The first step in designing a damping control system is to model the dynamics of the robotic system in the appropriate form under all possible conditions (e.g., various loading conditions). This results in a family of models. Using these models, the parameters of $H_{p}$ and $H_{v}$ are designed.

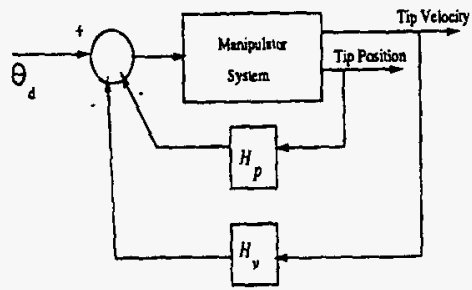

FIGURE 2. Feedback Control Structure

\subsection{SYSTEM MODELING}

Two levels of modeling are required for the manipulator system. The first level involves nonlinear modeling using the DADS program. This model acts as a testing ground for controller methodology development prior to implementation in the test bed. The second level of modeling involves representing the dynamics of the system with a set of linear constant-coefficient differential equations. This set of models (termed the control design models (CDMs)) are required for choosing parameters in the feedback controllers.

There are two possible approaches for developing the CDMs. With one approach the DADS model is linearized about a set of operating conditions. The second approach is to use a system identification method to optimally fit lin- 
ear models to the input-output data of the DADS model. This second method has a clear advantage in that it can be directly applied to the fiexible system through laboratory tests; therefore, the controller design is not dependent on the accuracy of the DADS model.

The CDMs for the flexible manipulator system at PNL are developed using the system identification approach. Prony analysis [7] is used to identify linear transfer functions based on the step response of the robotic system. A step function is applied to the azimuth angle of the SRM and the LRM tip response signals are measured. The responses are then analyzed using Prony analysis to identify optimal linear transfer function models. The identification process is perfomed under various loading conditions to obtain a family of transfer functions.

Prony analysis is very well suited for developing models of high-order linear oscillatory systems [8]. The Prony analysis software used at PNL is called IPRONYI [9]and is an advancement of a program developed by the Bonneville Power Administration used to analyze electromechanical oscillatory dynamics in large power systems.

Sixth to tenth order CDMs are identified for the test bed simulated on the DADS under two operating conditions: 1) no load on the SRM; and 2) full load on the SRM. The frequency response of the CDM's are shown in Figure 3 and Figure 4. The responses match the flexible manipulator's true response very closely. Note the change in the mode locations for the different loading conditions

\section{0 .CONTROLLER DESIGN METHODOLOGY}

From Figure 3, one sees that the transfer function for the tip position is dominated by the first two modes. Therefore, a feedback loop for the tip position would have the most effect on these two modes. Likewise from Figure 4, the second and third modes are most easily affected by a feedback on the ip velocity.

Modal gain alone does not determine the best feedback structure; phase must also be con- sidered. Figure 5 and Figure 6 show the rootlocus plots for the tip position and velocity transfer functions under full load conditions with constant gain feedback. For both signals, the loci move in opposite directions, i.e., their phasing is opposite. Mode 3 loci move in the same general directions as mode 2 . This phasing is challenging for feedback control.

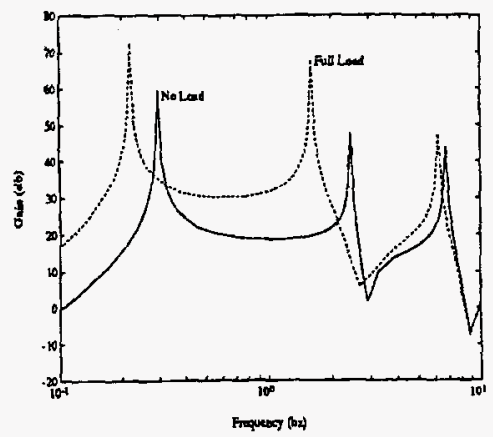

FIGURE 3. Response from azimuth angle to LRM tip position, open loop.

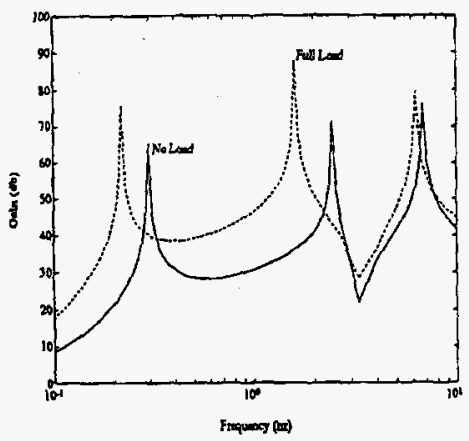

FIGURE 4. Response from azimuth angle to LRM tip velocity, open loop. 
In the no-load case, similar phasing occurs. The angle of departure for the three modes are very similar to the full-load case. Therefore, a controller that properly adjusts the phasing for one case, will do the same for the other.

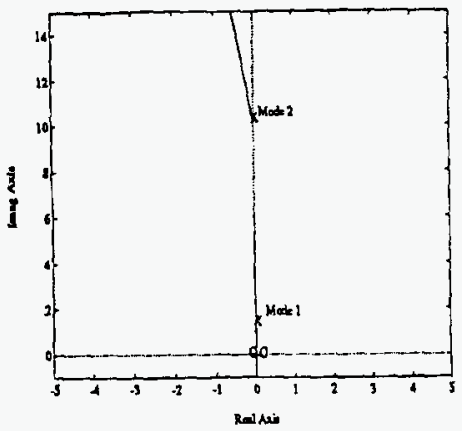

FIGURE 5. Root Locus Plot for Tip Position, Full Load

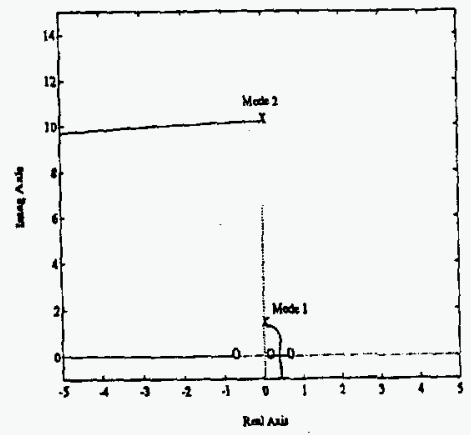

FIGURE 6. Root Locus Plot for Tip Velocity, Full Load

One solution to choosing a feedback controllers is to design $H_{p}$ and $H$, to provide damping to different modes. Because the tip-position transfer function has a high gain for mode 1 and requires phase-lag (evident from Figure 5) for adding damping to mode $1, H_{p}$ is designed to damp mode 1 while having little or no effect on modes 2 and 3. Controller $H_{v}$ is used to damp modes 2 and 3 while having very little effect on mode 1 . Also, both controllers are required to have significant roll-off properties outside their effective bandwidth. Forcing $H_{p}$ and $H$, to control different modes makes them highly decoupled which inherently results in a reliabie control structure.

The structure for $H_{p}$ and $H_{y}$ is a series of lead-lag blocks with an overall gain, which can be written in the Laplace domain as

$$
\begin{aligned}
& H_{p}(s)=\frac{K_{p}\left(s+b_{p, 1}\right)\left(s+b_{p, 2}\right) \ldots}{\left(s+a_{p, 1}\right)\left(s+a_{p, 2}\right) \ldots} \\
& H_{v}(s)=\frac{K_{v}\left(s+b_{v, 1}\right)\left(s+b_{v, 2}\right) \ldots}{\left(s+a_{v, 1}\right)\left(s+a_{v, 2}\right) \ldots}
\end{aligned}
$$

Sequential loop-closure $[10]$ is used to design the controllers. First the parameters of $H_{v}$ are chosen and that loop is closed, then the parameters of $H_{p}$ are chosen using the system with $H_{4}$ closed as the design model. The full load CDMs are used to design the control parameters because this represents the highest gain condition (as seen in Figures 3 and 4).

Once parameters have been chosen, the reliability and robusmess of the controllers are tested. Robustress tests are passed if the controllers provide a specified degree of damping and stability margin under all operating conditions. The tests are based on the system satisfying a minimum Nyquist circle criterion (which guarantee certain gain and phase margins) for both full load and no load operating conditions. The controller is deemed reliable if the system remains stable under all loading conditions and possible sensor failures. In this case this requires testing both position sensor and velocity sensor failures for both loading conditions. Parameters are adjusted until reliability and robustness criteria are met.

The methodology for choosing the parameters for $H_{p}$ and $H_{v}$ involves a somewhat ad hoc procedure primarily based on the concepts of 
loop-shaping [11] and root-locus design. The coefficients of $H_{p}$ are chosen to provide the proper phase to the make the pole representing mode 1 move farther into the left-hand-plane while having very little effect on modes 2 and 3 . $H_{\text {v }}$ is adjusted so that it provides proper phasing to modes 2 and 3 . while having little effect on mode 1.

Both controllers are designed to have low gain at frequencies higher than the third mode to avoid control spillover (i.e., unexpected effects on higher unmodeled modes). Effects on modes higher than the 3rd are expected to be very small, as initial analysis indicates that these higher modes are not excited for the robotic system.

The control design methodology is applied to the DADS model of the robotic system resulting in the following controllers:

$$
\begin{gathered}
H_{p}(s)=\frac{3.2}{(s+0.2)(s+5.0)(s+10.0)} \\
H_{v}(s)=\frac{0.073(s+1.0)}{(s+65.0)(s+15.0)}
\end{gathered}
$$

Figures 7 and 8 show the frequency response for the closed-loop system. The damping ratio for mode one increases from 0.0024 to 0.5914 in the full-load case, and increases from 0.0035 to 0.1117 in the no-load case. The damping ratio for mode two changes from 0.0032 to 0.0491 for full load, and 0.0043 to 0.0162 for no load. Changes for mode three are 0.0071 to 0.0707 for full load, and 0.0064 to 0.0454 for no load

The system is very robust and reliable. The worst robustness occurs when the sensor for $H_{p}$ fails. In this case the gain margin is guaranteed to be greater than $3.5 \mathrm{db}$, and the phase margin greater than 47 degrees (using a Nyquist circle criterion). This means the gain of the velocity controller could nearly double and the phase could change 47 degrees before mode 1 became unstable.

Also, because the controllers are decoupled, failure of $H_{p}$ has little effect on the damping of modes 2 and 3, and similarly, the failure of $H_{v}$ has little effect on the damping of mode 1 .

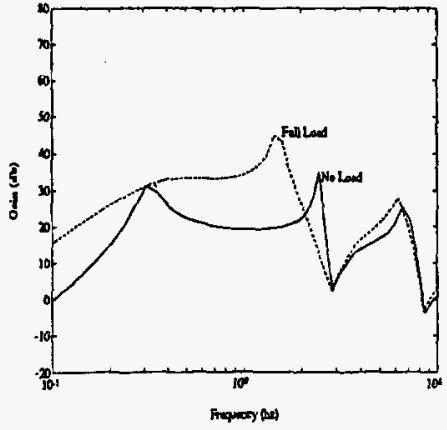

FIGURE 7. Closed-Loop Frequency Response for LRM Position

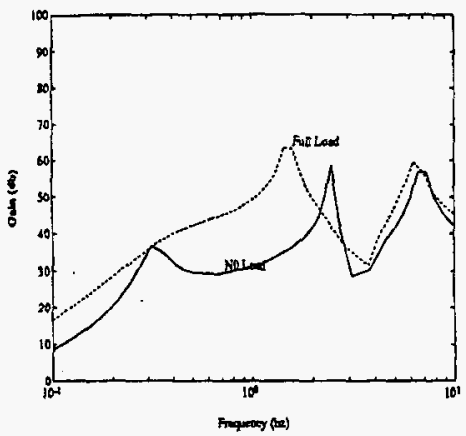

FIGURE 8. Closed Loop Frequency Response for LRM Velocity

\subsection{INITIAL RESULTS OF DAMPING CONTROL}

Using the control parameters in Equations 3 and 4, damping controllers are implemented on the DADS computer model of the test-bed.The simulation results presented in this section demonstrate that the control algo- 
rithms developed by this methodology can effectively damp oscillations in the strueture.

Figures 9 and 10 show the robotic system response to a step function of 0.1 radians in the desired azimuth angle $\theta_{d}$, and Figure 11 shows the controiled azimuth angle applied to the SRM under full load. The damping is considerably improved with little motion required of the SRM.

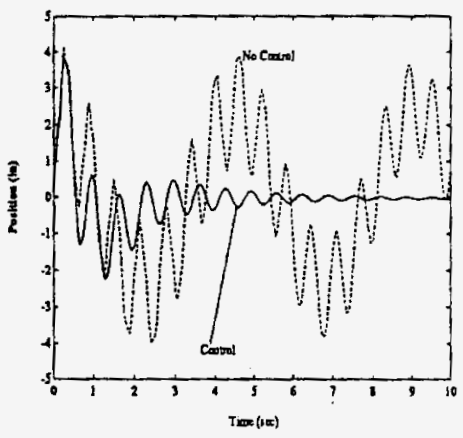

FTGURE 9. Step Response of LRM Tip Position, Full Load with Both $H_{p}$ and $H_{v}$.

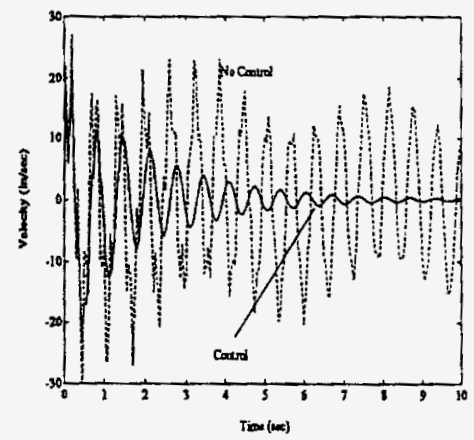

FIGURE 10. Step Response of LRM Tip Velocity, Full Load with Both $H$, and $H_{v}$.

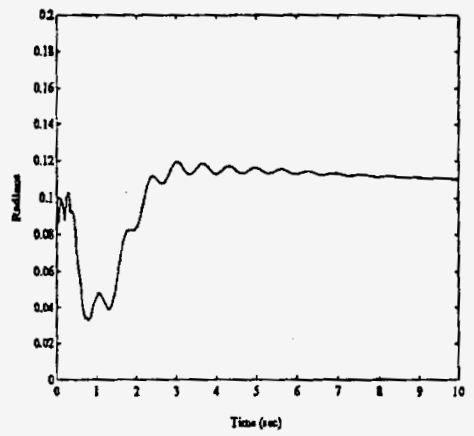

FIGURE 11. Controlled Azimuth Angle for Response in Figure 9.

Figures 12 and 13 show the step response under no load. Under no loading, the controlled damping is not as high because the robotic system gain is less. That is, the SRM has more leverage when it is carrying a load. The no-load damping could be improved by increasing the gain of the controllers, but this would jeopardize the controllers reliability and robustness at the full load condition. This is the cost of forcing the control system to be robust.

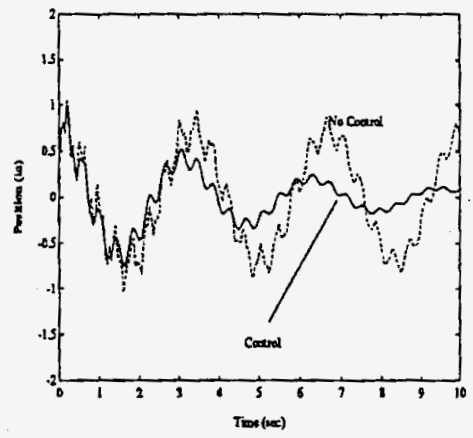

FIGURE 12. Step Response of LRM Tip Position, No Load with Both $H_{p}$ and $H_{v}$. 


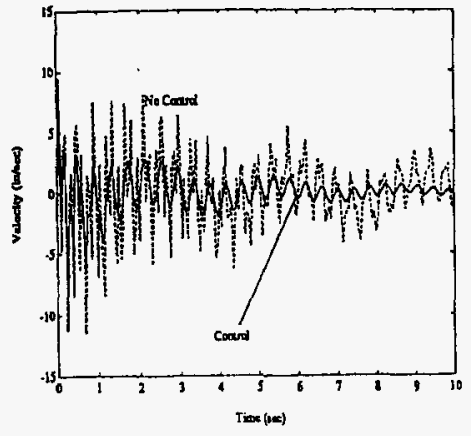

FIGURE 13. Step Response of LRM Tip Velocity, No Load with Both $H_{p}$ and $H_{v}$.

The controller reliability is demonstrated in Figures 14 and 15. Figure 14 shows the system response with controller $H_{\text {v }}$ removed (simulating a velocity sensor failure). In this case, $H$, still performs well. The loss of $H_{p}$ is shown in Figure 15. Note that the second and third modes are still damped in this case by $H_{v}$.

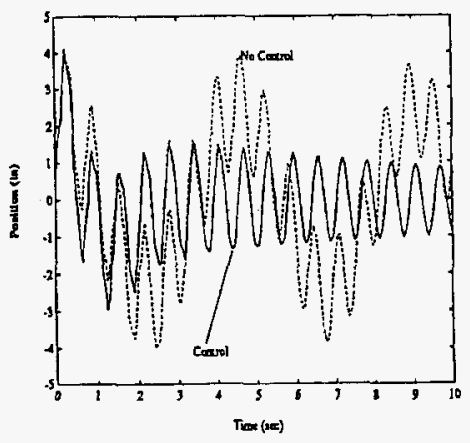

FIGURE 14. Step Response of LRM Tip Position, Full Load With $H_{p}$ Only.

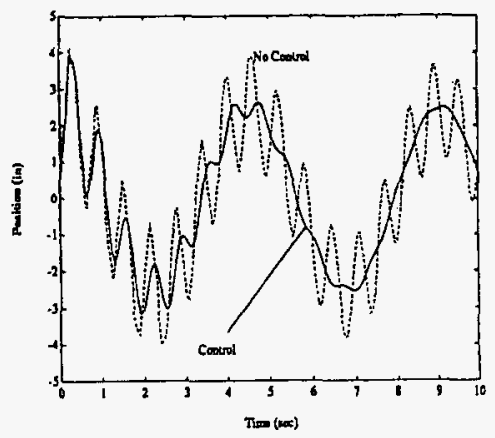

FIGURE 15. Step Response of LRM Tip Position, Full Load With $H_{v}$ Only.

\subsection{CONCLUSIONS}

The results presented here demonstrate that oscillations in a long manipulator can be damped using the inerial forces of a small one attached to its tip. A fixed-parameter damping controller is designed for a detailed computer model of a test-bed. The controller is required to be robust in that it provides damping over all loading conditions. It is also required to be reliable in that it must perforn well under sensor failures. The controllers are designed based on a set of linear models obtained through a parameter identification scheme which uses measurement test data to construct system models.

Because the control system is forced to perform over a wide range of loading conditions, it sacrifices some damping under no load. A possible alternative that may be investigated in the future is to use gain scheduling to adjust the controller gain based on loading as well as other more advanced design methodologies.

Other furure work includes applying the control design methodology described here to the laboratory test-bed. Aiso, configurations that allow more degrees of freedom for the test bed will be investigated. 


\section{REFERENCES}

1. W. J. Book and S. H. Lee, "Vibration Control of Large Fexible Manipulator by Small Robotic Am," Proceedings of the 1989 American Control Conference, Vol. 2, pp. 1377-1380, June 1989.

2. S. Yurkovich and A. P. Tzes, "Experiments in Identification and Control of FlexibleLink Manipulators," IEEE Control Systems Magazine, pp. 41-46, Feb. 1990.

3. P. T. Komik, S. Yutkovich, and U. Ozguner, "Acceleration Feedback for Control of a Flexible Am," Journal of Robotic Systems. Vol. $5 \mathrm{~m}$ No. 3, pp. 181-196, June 1988.

4. R. H. Cannon and E. Schmitz, "Initial Experiments on the End-Point Control of a Flexible One-Link Robot," The International Journal of Robotics Research, Vol. 3. No. 3. pp. 62-75, Fall 1994.

5. B. Yuan, W. J. Book, and B. Siciliano, "Direct Adaptive Control of a One-Link Fexible Amn with Tracking." Journal of Robotic Systems, Vol. 6. No. 6, pp. 663-680.

6. M. S. Evans, D. J. Trudnowski, and C. P. Baker, "Studies in Control of Long Reach Flexible Manipulators," To be presented at the American Nuclear Society International Conference, Chicago, Illinois, Nov, 1992.

7. D. Pierre, D. Trudnowskj, J. Hauer, "Identifying Linear Reduced-Order Models for Systems with Arbitrary Initial Conditions Using Prony Signal Analysis," IEEE Trans. on Automatic Control, Vol. 37, No. 6, pp. 831-835. June 1992

8. .D. Trudnowski, "Characteristics of Identifying Linear Dynamic Models Using Prony Analysis," pending PNL report.

9. D. Trudnowski, "IPRONYID Version 1.lb: A Computer Program for the Identification of Transfer Functions using Prony Analysis." pending PNL report.
10. J. M. Maciejowski, Multivariable Feedback Design. New York: Addison-Wesley Publishing, 1989.

11. J. Doyle, B. Francis, and A. Tannenbaum, Feedback Control Theony. New York: Macmillan Publishing. 1992. 


\section{DISTRIBUTION SHEET}

\begin{tabular}{|c|c|c|c|c|c|}
\hline \multirow{2}{*}{$\begin{array}{l}\text { To } \\
\text { Distribution }\end{array}$} & \multirow{2}{*}{\multicolumn{3}{|c|}{$\begin{array}{l}\text { From } \\
\text { Retrieval Engineering } 73530\end{array}$}} & \multicolumn{2}{|l|}{ Page 1 of 1} \\
\hline & & & & \multicolumn{2}{|c|}{ Date $8 / 20 / 96$} \\
\hline \multirow{2}{*}{\multicolumn{4}{|c|}{$\begin{array}{l}\text { Project Title/Work Order } \\
\text { Issues Associated with Manipulator-based Waste Retrieval from } \\
\text { Hanford Underground Storage Tanks with a Preliminary Review of } \\
\text { Commercial Concepts/D2027 WHC-SD-TA-181, Rev. } 0\end{array}$}} & \multicolumn{2}{|c|}{ EDT No. 605674} \\
\hline & & & & \multicolumn{2}{|l|}{ ECN No. } \\
\hline Name & MSIN & $\begin{array}{c}\text { Text } \\
\text { With All } \\
\text { Attach. }\end{array}$ & Text Only & $\begin{array}{l}\text { Attach./ } \\
\text { Appendix } \\
\text { Only }\end{array}$ & $\begin{array}{l}\text { EDT/ECN } \\
\text { Only }\end{array}$ \\
\hline $\begin{array}{l}\text { J. W. Bailey } \\
\text { E. J. Berglin } \\
\text { P. W. Gibbons } \\
\text { D. B. Hagmann } \\
\text { B. K. Hatchel } \\
\text { J. S. Hertzel } \\
\text { E. J. Kosiancic } \\
\text { R. P. Marshall } \\
\text { L. B. McDaniel } \\
\text { G. A. Meyer } \\
\text { D. L. Morgan } \\
\text { D. C. Ramsower } \\
\text { M. W. Rinker } \\
\text { W. R. Wrzesinski } \\
\text { J. A. Yount } \\
\text { Central Files }\end{array}$ & $\begin{array}{l}S 2-48 \\
H 5-61 \\
H 5-61 \\
H 5-61 \\
K 5-26 \\
H 5-61 \\
H 5-61 \\
H 5-61 \\
H 5-61 \\
S 2-48 \\
G 6-55 \\
H 5-61 \\
K 5-22 \\
S 7-53 \\
H 5-61 \\
A 3-88\end{array}$ & $\begin{array}{l}x \\
x \\
x \\
x \\
x \\
x \\
x \\
x \\
x \\
x \\
x \\
x \\
x \\
x \\
x \\
x\end{array}$ & & & \\
\hline
\end{tabular}

